\title{
Chemical speciation and bioavailability of uranium in freshwaters: Illustration for a bivalve biological model used as contamination radioindicator
}

\author{
F. Denison, J. Garnier-Laplace, C. Adam and J.T. Smith ${ }^{1}$
}

\author{
Institut de Protection et de Surreté Nucléaire, DPRE, SERLAB, Laboratoire de Radioécologie \\ Expérimentale, CE Cadarache, bâtiment 186, BP. 1, 13108 Saint-Paul-lez-Durance, France \\ ${ }^{1}$ Centre for Ecology and Hydrology (CEH), Dorset, Winfrith Technology Centre, \\ Dorchester, Dorset DT2 8ZD, U.K.
}

\begin{abstract}
The transfer of contaminants from the environment to the biota depends on the abundance and availability of the contaminant in its various physico-chemical forms. To assess the bioavailability of uranium in the environment it is necessary to characterise the relative contributions of its physico-chemical fractions. A reductionistic approach has been employed to precise the system specific factors that regulate the uptake of uranium from the dissolved fraction by the freshwater bivalve species Corbicula fluminea in well defined conditions. Results from preliminary experiments are presented which demonstrate that it is pessible to apply this methodology to investigate which uranium solution species are able to be transferred to the biota.
\end{abstract}

\section{INTRODUCTION}

Uranium is a widely distributed naturally occurring element usually present in trace quantities. It has both a chemical and radiological toxicity and so could be a potential hazard to the biota in receptor ecosystems where its concentration is increased. Various anthropogenic activities can considerably enhance levels of uranium in the environment, particularly in surface waters. Certain aquatic organisms have been demonstrated to have the ability to bioaccumulate uranium $[1,2,3]$ indicating that this contaminant may be concentrated through the food chain.

In order to predict the impact of uranium contamination on the biota, it is important to understand the principle factors that control the transfer of uranium from the environment to the biotic compartment. Organisms respond to the totality of their usually complex and dynamic environment, and it is insufficient to define that environment by measuring selected physical and chemical parameters. This is due to both the impracticability (or impossibility) of sufficiently characterising the system and also the limited knowledge of the interaction of toxicants (antagonistic or synergistic effects) and the effect of other stress factors (temperature, water velocity, dissolved oxygen concentration, etc.). Equally it is insufficient to consider the biological status in isolation from a comprehensive physical and chemical characterisation of the system, if a greater understanding of the controlling parameters is to be achieved, and hence the development of a predictive ability that can be applied to different ecosystems.

In-situ biomonitoring is frequently used as a technique to assess changes in the quality of the environment [4], by measuring one or several biomarkers of exposure and the effects on model organisms, such as the accumulation of the contaminant/contaminants, behavioural changes or biochemical perturbations. To realise such a program for the monitoring of uranium contaminated sites it is necessary to characterise both the suitability of the chosen biological models and the principal factors, both biotic and abiotic, influencing the uptake of uranium by the organisms. There are a number of factors that influence the transfer of contaminants from the environmental medium to the biota, which may be classed as three groups of factors: the physico-chemical characteristics of the medium, biological factors and the nature of the contamination. These 3 factors are interrelated and must be considered as an ensemble. The physico-chemical characteristics of the medium exert both a direct effect on the biota, such as behavioural or physiological changes (water processing and filtration rate of bivalves, and metabolic rate [5]) and also the form of the contaminant in the environmental medium (physico-chemical speciation). Biotic factors at an individual organism level such as the behaviour, the physiological state of 
the individual and the interactions of the contaminant with the biological membrane play a significant role in regulating the transfer rate of the contaminant. The nature of the contamination, both of the source term and its subsequent transformations in the environment also plays a significant role in determining the bioavailability of the contaminant in a specific system.

The total concentration of a contaminant is generally not a good indicator of its bioavailability; this is especially true for uranium that has a very extensive and complex solution chemistry. The system specific physico-chemical speciation of uranium, i.e. its distribution among various possible species may be usefully described by its physical speciation, i.e. the distribution between dissolved, colloidal and particulate species, and its chemical solution speciation. The colloidal and particulate fractions can be very significant in some waters contributing up to $90 \%$ of the total uranium concentration, potentially providing a significant contamination source if these compartments are assimilated by the organisms, for example the ingestion of algae by filter-feeding organisms (trophic transfer). In the dissolved fraction in oxidising conditions uranium as the uranyl species readily forms complexes with hydroxide, carbonate, phosphate and many organic ligands. This speciation has a significant effect on the bioavailability of the dissolved fraction, for example influencing the abundance of cell membrane surface complexes capable of being transported across the biological barrier [6,7].

An experimental program of complementary short-duration well-defined laboratory experiments in simplified conditions, medium-term regulated experiments in a laboratory fluvial mesocosm and long. term in-situ field experiments is being undertaken to elucidate the principal controlling factors governing uranium bioavailability in the environment. The biological models selected are two bivalve species, Corbicula fluminea and Dreissena polymorpha. These species have been extensively used as bioindicators due to their robustness and the fact that their feeding strategy and means of respiration ensures a high throughput of the environmental medium, and allows the concurrent uptake of the contaminant from a range of the available physico-chemical forms $[8,9]$. Initial experiments have been performed to investigate the direct uptake and organotropism of uranium from the dissolved phase by Corbicula fluminea during short-duration exposures in well defined and regulated solution compositions. The direct transfer kinetics from seven different solution compositions has been measured, investigating the effect of $\mathrm{pH}$ and total uranium concentration on the bioavailability.

\section{MATERIALS AND METHODS}

\subsection{The effect of $\mathrm{pH}$ on the bioavailability of uranium (experiment 1)}

The objective of this preliminary experiment was to assess the role of $\mathrm{pH}$ in controlling uranium bioavailability. Exposures were performed in a synthetic media with the following major ion concentrations: $[\mathrm{Ca}]=1.5 \mathrm{mM} ;[\mathrm{Mg}]=0.5 \mathrm{mM} ;[\mathrm{Na}]=1 \mathrm{mM} ;[\mathrm{K}]=0.5 \mathrm{mM} ;[\mathrm{Cl}]=3 \mathrm{mM} ;\left[\mathrm{NO}_{3}\right]=1.5$ $\mathrm{mM} ;\left[\mathrm{SO}_{4}\right]=0.5 \mathrm{mM}$. This approach facilitates the interpretation of the data in terms of the chemical speciation of uranium and excludes the presence of organic ligands; the absence of added carbonate simplifies the solution speciation of uranium, although carbonate containing complexes are still present and become significant at higher $\mathrm{pH}$ values due to the atmospheric equilibrium with $\mathrm{CO}_{2}$.

C. fluminea individuals were cleaned and then acclimatised to the exposure medium at a density of less than 10 individuals per litre of solution in aquaria containing acid cleaned sand. The water used to conserve the organisms in the laboratory (tap water) was gradually replaced by the artificial solution over a period of 2 days, the organisms were then kept in the artificial solution for a further 8 days with regular changes of solution to maintain a constant composition. The organisms were observed to be filtering at a comparable rate to before the start of the acclimatisation indicating that perturbation due to the solution composition was minimal. The aquaria were maintained at a constant temperature of $20 \pm 0.2^{\circ} \mathrm{C}$ in a water bath, and the photoperiod was 12 hours illumination/ 12 hours darkness. The $\mathrm{pH}$ of the solutions was measured frequently and regulated by appropriate additions of mineral acid $(\mathrm{HCl})$ or base $(\mathrm{NaOH})$.

The conditions of the uranium contamination were chosen with the dual objectives of minimising perturbation due to the direct toxicity of uranium, whilst providing sufficiently high concentrations to observe uptake. To this end the results of Markich et al. (2000) [10] were used to calculate the total 
uranium concentrations in solutions at $3 \mathrm{pH}$ values: $5.5,6.0$ and 6.5 . This work was based on the measurement of valve movement response of the bivalve Velesunio angasi to uranium, and established a relationship between the biological response (BR) and a weighted sum of the calculated free-ion and first hydrolysis product concentrations, namely:

$$
\mathrm{BR} \propto 1.86 \cdot\left[\mathrm{UO}_{2}^{2+}\right]+\left[\mathrm{UO}_{2} \mathrm{OH}^{+}\right]
$$

The maximum "no-effect" sum concentration found by Markich et al. was $100 \mu \mathrm{g} / \mathrm{l}$ and total solution concentrations were calculated from this constant value for the $3 \mathrm{pH}$ values selected, namely 200,500 and $2000 \mu \mathrm{g} / \mathrm{l}$ uranium at $\mathrm{pH}$ values of 5.5, 6.0 and 6.5 respectively. The geochemical speciation code JChess [11] using a database compiled from the OECD/NEA thermochemical data base project [12] was used to perform the solution speciation calculations.

Contamination was commenced 1 hour after the start of the light phase of the photoperiod by transplanting the acclimatised organisms from the aquaria to exposure vessels containing the synthetic media contaminated in uranium by addition of uranyl nitrate solutions. Samples of $C$. fluminea and water were taken at intervals during the 8 hours exposure time, and the $\mathrm{pH}$ regulated at frequent intervals by the addition of mineral acid/ base. The water samples were analysed for total uranium content (ICP-OES, limit of detection $50 \mu \mathrm{g}-\mathrm{U} / \mathrm{/})$ and major ion concentrations (ion chromatography). The uranium concentrations of the dissected soft body tissues of the $C$. fluminea samples were measured after acid digestion ( $<1 \mathrm{~g}$ wet tissue, $3 \mathrm{ml}$ concentrated nitric acid, $105^{\circ} \mathrm{C}$ for 3 hours in sealed tubes) by ICP-OES.

\subsection{The organotropism of uranium after short-duration direct exposure (experiment 2)}

An initial investigation of the tissue distribution of uranium in organisms contaminated during a shortterm exposure has been performed. Samples of $C$. fluminea were contaminated in the same synthetic medium as used previously, the dissolved uranium concentration was $500 \mu \mathrm{g} / \mathrm{l}$ and the $\mathrm{pH}$ regulated at a value of 6.5. After an exposure time of 8 hours, the organisms were removed from the exposure medium and frozen immediately. After partial thawing, to facilitate dissection of the individuals, the soft bodies were dissected to an organ level (gills, muscular mass, visceral mass, mantle), the organs digested individually and the uranium concentrations measured as previously.

\section{RESULTS}

\subsection{Experiment 1 - the effect of pH and total uranium concentration}

As can be seen in Figure 1, the major ion composition and $\mathrm{pH}$ of the exposure medium was consistent during the course of the experiment.

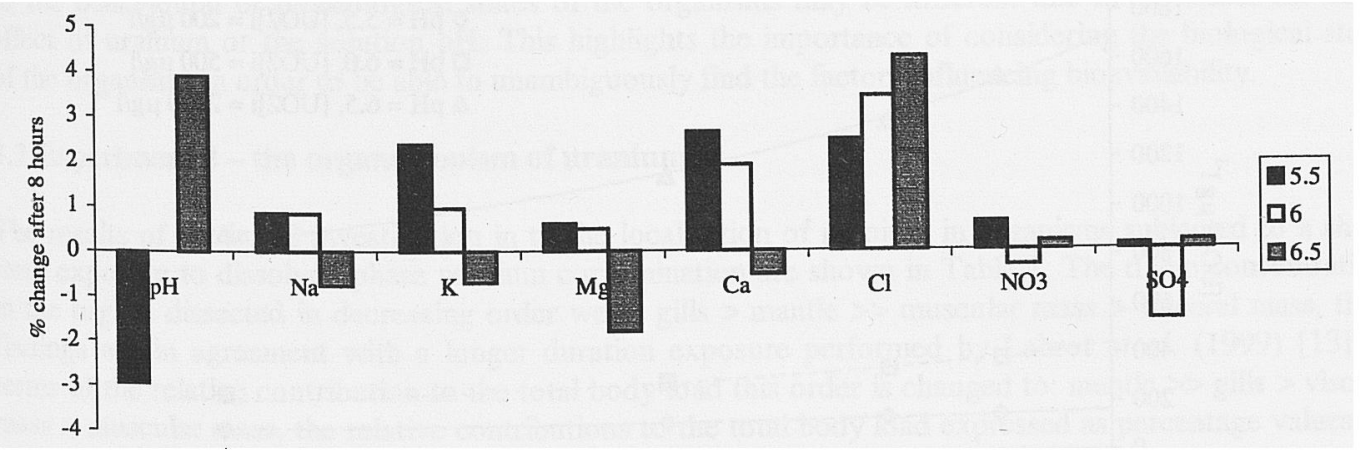

Figure 1. Evolution of the composition of the exposure medium, percentage change during the 8-hour exposure. 
The whole soft-body uranium concentrations in $C$. fluminea increased during the course of the exposure experiment as shown in Figure 2. The tissue concentrations in the exposure conditions of pH 5.5, [UO $]_{\mathrm{T}}$ $=200 \mu \mathrm{g} / 1$ and $\mathrm{pH} 6.0,\left[\mathrm{UO}_{2}\right]_{\mathrm{T}}=500 \mu \mathrm{g} / \mathrm{l}$ were not significantly different at any sample time (t-test, $\mathrm{P}<$ 0.05 ), whereas the concentrations at $\mathrm{pH} 6.5,\left[\mathrm{UO}_{2}\right]_{\mathrm{T}}=2000 \mu \mathrm{g} / 1$ were considerably higher, approximately five times greater than the other two conditions after 8 hours.

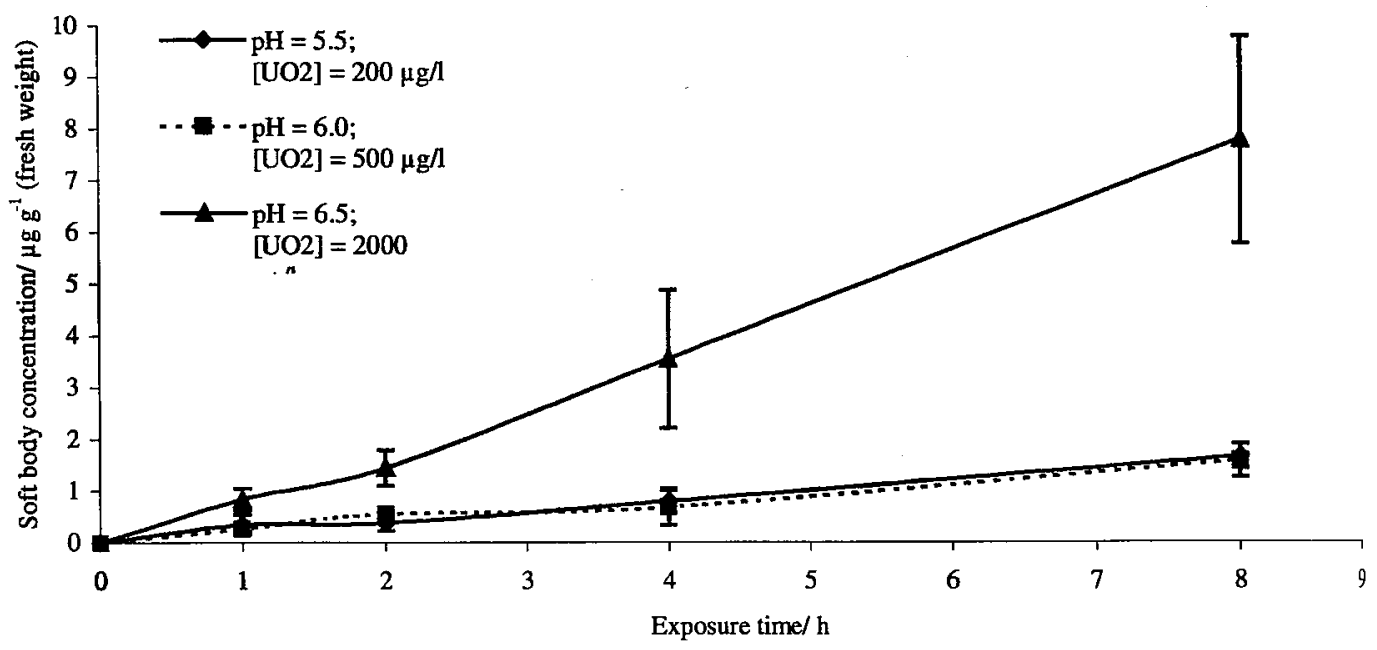

Figure 2. Whole soft body uranium concentrations in $C$. fluminea during the 8-hour exposure experiment.

The total concentration of uranium in solution decreased markedly during the exposure period, due to sorption on the sand in the exposure tanks. To permit calculation of the bioconcentration factors of uranium at each sample time, a second order kinetics equation was fitted to the dissolved uranium data of the form:

$$
C_{t}=\frac{C_{0}}{1+C_{0} \cdot k \cdot t}
$$

where $\mathrm{C}_{\mathrm{t}}$ is the concentration at time, $\mathrm{t}, \mathrm{C}_{0}$ is the concentration at $\mathrm{t}=0$ and $\mathrm{k}$ is the rate constant. The solution concentrations and the fitted kinetic equations are shown in Figure 3.

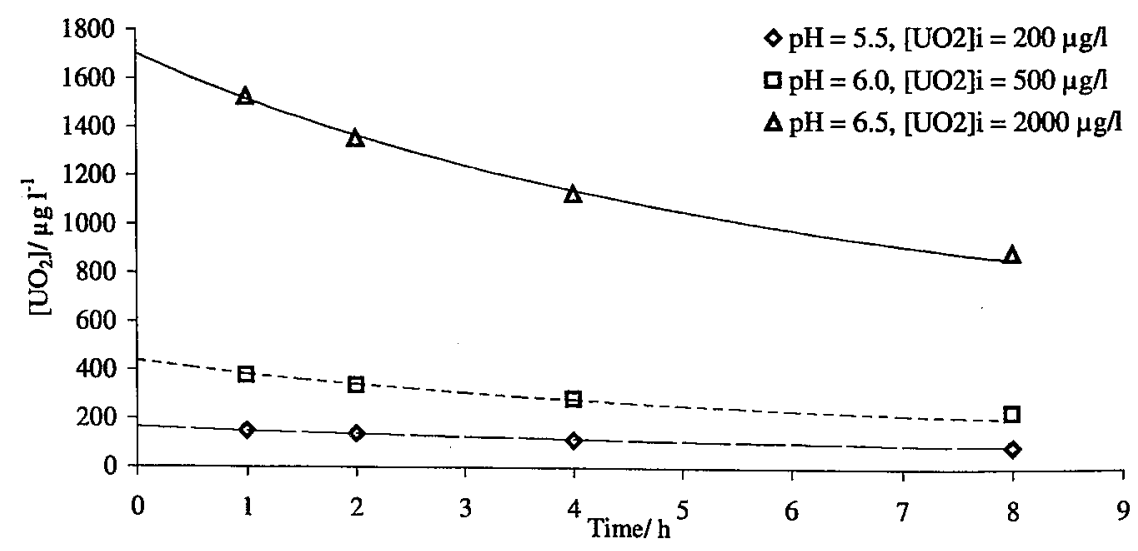

Figure 3. The evolution of dissolved uranium during the exposure experiments and the fitted kinetic equations. 
To calculate the bioconcentration factors at each time interval, t, the tissue concentrations $(\mu \mathrm{g}-\mathrm{U} / \mathrm{kg}$ fresh weight) were divided by the kinetic equation integrated over the same time interval, i.e.

$$
\int_{0}^{t} C_{t} d t / \Delta t
$$

The bioconcentration (BCF) factors calculated in terms of the total solution uranium concentration range from 5 to 14 after the 8-hour exposure with the highest calculated $\mathrm{BCF}$ in the $\mathrm{pH} 5.5,\left[\mathrm{UO}_{2}\right]_{\mathrm{T}}=200 \mu \mathrm{g} / 1$ exposure condition, the other two conditions providing similar values. Bioconcentration factors in terms the weighted sum of the free uranyl ion and first hydrolysis product concentrations according to the Markich relationship were also calculated and are shown in Figure 4.

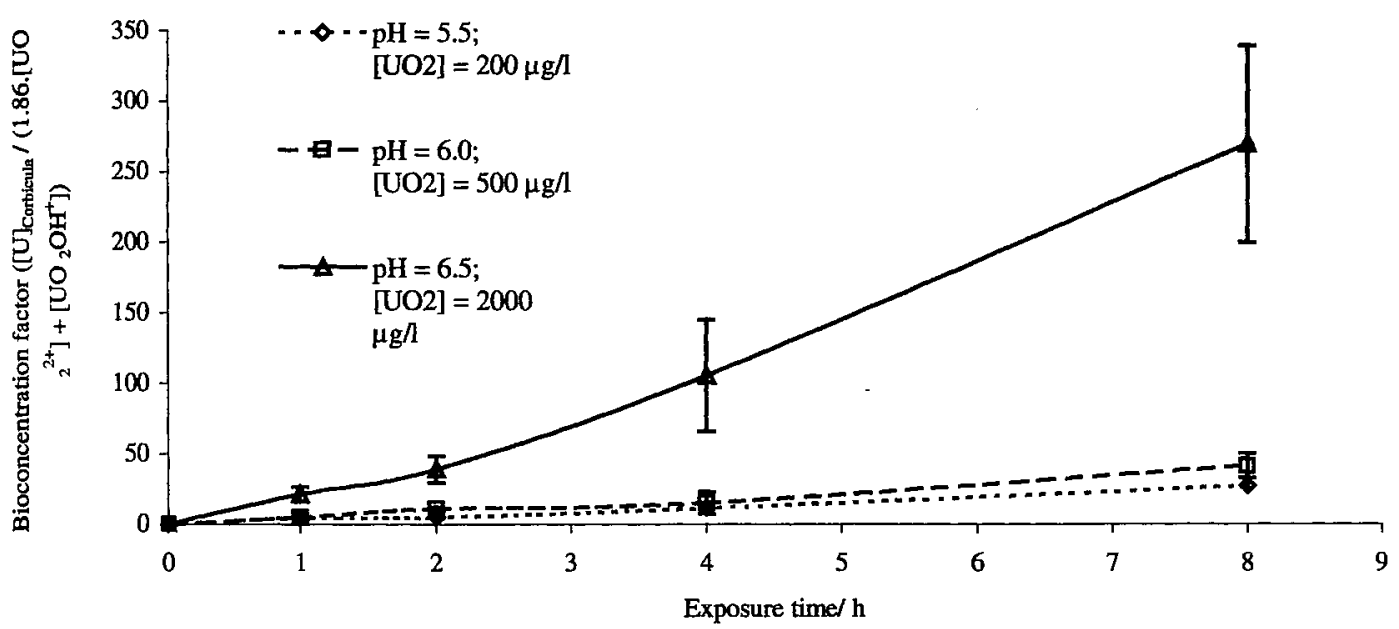

Figure 4. Bioconcentration factors during the exposure experiment expressed in terms of the Markich relationship [10].

The trends are the same as those found for the tissue concentrations, due to the manner in which the exposure solution were designed i.e. a constant value for the weighted sum of these two solution species. These data show that this simple relationship is not valid either for this range of solution composition, or for $C$. fluminea. There are a number of possible reasons for this, such as the expression may not adequately describe the significant bioavailable solution species over this range of solution composition, or the behavioural or physiological states of the organisms may be different due to the either the direct effect of uranium or the solution $\mathrm{pH}$. This highlights the importance of considering the biological status of the organisms in order to be able to unambiguously find the factors influencing bioavailability.

\subsection{Experiment 2 - the organotropism of uranium}

The results of the initial investigation in to the localisation of uranium in organisms subjected to a shortterm exposure to dissolved phase uranium contamination are shown in Table 1 . The tissue concentrations in the organs dissected in decreasing order were: gills $>$ mantle $>>$ muscular mass $>$ visceral mass, these findings are in agreement with a longer duration exposure performed by Labrot et al. (1999) [13]. In terms of the relative contribution to the total body load this order is changed to: mantle $>>$ gills > visceral mass $>$ muscular mass, the relative contributions to the total body load expressed as percentage values are also given in Table 1 
Table1. The tissular distribution of uranium after a short-term exposure.

\begin{tabular}{lcc}
\hline Tissue type & $\begin{array}{c}\text { Uranium concentration/ } \\
\mu \mathrm{g}-\mathrm{U} \mathrm{g}^{-1} \text { fresh weight }\end{array}$ & $\begin{array}{c}\text { Percentage contribution } \\
\text { to total body load }\end{array}$ \\
\hline gills & 30.9 & 23 \\
muscular mass & 9.5 & 13 \\
visceral mass & 4.3 & 13 \\
mantle & 28.8 & 51 \\
\hline
\end{tabular}

\section{DISCUSSION AND CONCLUSIONS}

These preliminary experiments show that it is possible to perform short-term exposures to uranium contamination in well-defined and regulated solution media to investigate the influence of solution speciation on the transfer of uranium to aquatic bivalves. Tissue concentrations are both measurable and significantly higher than background levels after short time periods. The transfer of uranium to the organisms has a strong dependence on the solution composition and the total solution concentration is nol a good indicator of the bioavailability. The relationship proposed by Markich et al. to describe the value movement response of a bivalve to uranium contamination was found to be inadequate in describing the uptake of uranium from simplified solutions for the $\mathrm{pH}$ range of 5.5 to 6.5. The uncertainty in the interpretation of the results due to the behavioural and physiological state of the organisms not beim characterised highlights the importance of considering this factor in the study of the transfer of contaminants to the biota. The results from the organotropism study were consistent with published date from a longer-term exposure, indicating that the inter-organ migration of uranium occurs rapidly.

\section{References}

[1] Haas, J.R., Bailey, E.H., Purvis, O.W., Amerciacn mineralogist, 83 (1998) 1494-1502.

[2] Labrot, F., Narbonne, J.F., Ville, P., Saint Denis, M., Ribera, D., Arch. environ. contam. toxicol. 36 (1999) 167-178.

[3] Poston, T.M., Bull. environm. contam. toxicol. 28 (1982) 682-690.

[4] Bayne, B.L., Water Sci. Technol. 21 (1989) 1089-1100.

[5] Tran, D., Ph.D. dissertation. LUniversite Bordeaux 1, Bordeaux. (2001) pp 140.

[6] Campbell, P.G.C., In: Tessier, A., and Turner, D.R., (Ed.) Metal Speciation and Bioavailability in Aquatic Systems (John Wiley and Sons, 1995) pp 45-102.

[7] Brown, P.L., Markich, S.J., Aquatic Toxicology 51 (2000) 177-194.

[8] Roditi, H.A., Fisher, N.S., Limnology and Oceanography 44 (1999) 1730-1749.

[9] Fraysse, B., Baudin, J.P., Garnier-Laplace, J., Boudou, A., Ribeyre, F., Adam, C., Bulletin of Environmental Contamination and Toxicology 65 (2000) 638-645.

[10] Markich, S.J., Brown, P.L., Jeffree, R.A., Lim, R.P., Aquatic Toxicology 51 (2000) 155-175.

[11] Van der Lee, J., Thermodynamic and mathematical concepts of Chess, École des Mines de Paris, (1998) Technical Report LHM/RD/98/39.

[12] Grenthe, I., Fuger, J., Konings, R.J.M., Lemire, R.J., Muller, A.B., Nguyen-Trung, C., Wanner, H. , Chemical Thermodynamics of Uranium (Elsevier Science Publishers B.V.: Amsterdam, 1992). 